\title{
Nuclear Analysis of the ITER In-Vessel Viewing System
}

Anton Travleev $^{\mathrm{a}^{*}}$, Yuefeng Qiu ${ }^{\mathrm{a}}$, Ulrich Fischer ${ }^{\mathrm{a}}$, Raul Pampin ${ }^{\mathrm{b}}$, Adrian Puiu $^{\mathrm{b}}$, Roger Reichle ${ }^{\mathrm{c}}$, Davide Flammini $^{\mathrm{d}}$ and Rosaria Villari ${ }^{\mathrm{d}}$

${ }^{a}$ Karlsruhe Institute of Technology, Hermann-von-Helmholtz-Platz 1, D-76344 EggensteinLeopoldshafen, Germany

${ }^{b}$ Fusion for Energy, Calle Josep Pla 2,Torres Diagonal Litoral B3, 08019 Barcelona, Spain 'ITER Organization, Route de Vinon-sur-Verdon, CS 90 046, 13067 St. Paul Lez Durance CE DEX, France

${ }^{a}$ ENEA, FSN Department, ENEA C. R. Frascati, via E. Fermi 45, 00044 Frascati (Roma), Italy

*Corresponding author: anton.travleev@kit.edu

The In-Vessel Viewing System (IVVS) is a diagnostic tool in ITER to perform in-vessel inspections between plasma pulses or during shutdown. Six identical units will be installed, each consisting of the scanning probe, the mobile assembly, shield blocks, the cartridge frame, and various actuators, drivers, motors, sensors and connectors. During plasma pulses, each of the units is parked inside a dedicated port extending from the outer wall of the vacuum vessel (VV) to the port cell (PC). The IVVS design must fulfill specific requirements related to the service lifetime of sensitive components and to the radiation effects on neighboring components.

This work is dedicated to the nuclear analysis of the latest IVVS design aiming at the proof that these requirements are fulfilled. A new MCNP model of the IVVS was built and integrated into the C-lite model of ITER. Relevant nuclear responses and radiation loads were provided both for plasma operation and shutdown periods. These include spatial maps of the neutron flux, the nuclear heating and absorbed dose rates throughout the considered IVVS port and some sensitive components. The activation analysis for the IVVS components provided the basis for the calculation of the shutdown dose rate (SDDR) distribution inside the port and the generation of a surface source of decay photons for use with the SDDR assessments of the PC. The neutron flux mapping shows improvements with respect to the previous design of neighbor components and gives insight to further possibilities of reducing nuclear loads to IVVS sensitive components. The activation analysis reveals that the major contributors to decay photon source are the movable shield counterweights.

This work was funded by F4E under contract F4E-OMF-466-T06. The views and opinions expressed herein do not necessarily reflect those of F4E or the ITER Organization.

Keywords: ITER, Nuclear analysis, IVVS, Shutdown dose rate

\begin{tabular}{|l|l} 
Topic Category & Nuclear System design
\end{tabular}


